\title{
The country profile
}

The Republic of Malta comprises 6 small islands covering an area of approximately 320 square $\mathrm{km}$. It is situated in the Mediterranean Sea, $93 \mathrm{~km}$ south of Sicily and $290 \mathrm{~km}$ north of the African Continent. Only 3 of the 6 islands are permanently inhabited. The largest city is Valletta, which is also the nation's capital. Malta is a bilingual state and both languages, Maltese and English, are official. Maltese is the most widely spoken language of the country with 90.2 per cent, followed by English with 6 per cent, multilingual 3 per cent and other 0.8 per cent.

Malta has been inhabited since prehistoric times. The country was first colonised by the Phoenicians, then the Romans, Arabs, Normans, the Knights Hospitallers of St. John of Jerusalem, and lately the British. Despite having been colonised for a long time, the age-old Maltese traditions managed to survive through the generations. The reliance on maritime trade has helped to shape and conserve what we now know as Maltese culture. Maltese are generally regarded as religious people and religion plays a fundamental role in their day-to-day living. The official Maltese religion is Roman Catholic, representing almost 97 per cent of the population.

Malta got its independence in 1964 after almost 150 years of British rule. After independence, the country became a member of the British Commonwealth, with a parliamentary democracy and Queen Elizabeth II as the head of state. On December 13, 1974, Malta became a fully independent republic and replaced the queen with an elected president. The president is appointed by parliament. In turn, the president appoints the prime minister, the leader of the party that wins a majority of seats in a general election for the unicameral (one chamber) House of Representatives.

Malta is a member of the European Union and continues to be an active participant in the United Nations, the Commonwealth, the Council of Europe, the Organization for Security and Co-operation in Europe (OSCE), World Trade Organization (WTO) and various other international organisations.

The constitution is the supreme law of the land and, besides setting up and regulating major institutions - such as parliament the executive and the judiciary - it has a chapter dealing with 'Declaration of Principles', which is fundamental to the governance of the country, and another chapter dealing with 'Fundamental Rights and Freedoms of the Individual'.

The population of Malta was estimated at 405,165 in July 2009. The population is characterised by a slow growth rate, low births and mortality, and an aging population. 
According to 2009 estimates, the age structure is distributed as follows: 0-14 years: 16.1 per cent, $15-64$ years: 69.4 per cent and 65 years and over: 14.5 per cent. The infant mortality rate is estimated around 5.94 deaths per 1,000 births. Life expectancy is 75.49 years for males and 80.62 for females. 